\title{
Creating New Roles for Libraries in Academic Research: Research Conducted at the University of Calgary, 2015-2020
}

\section{H. Thomas Hickerson, John Brosz, and Leonora Crema}

\begin{abstract}
A recently completed study at the University of Calgary has had broad professional impact and generated increased attention to the role of academic libraries in campus research. This multiyear, evidence-based study was conceived in recognition that the role libraries have traditionally played in research is of decreasing relevance. With support from The Andrew W. Mellon Foundation, this study employs intensive partnership among library staff, scholars, and research administrators to identify the transformational changes necessary for repositioning libraries in the research enterprise.
\end{abstract}

\section{Introduction}

The historic role in scientific and scholarly research upon which today's academic libraries were designed is of diminishing importance. Three principal and closely related areas of change have combined to produce this transformation:

- Information production, dissemination, and accessibility

- The nature, character, and scope of research

- Research methods and analytical tools

In the age of Open Access, Open Science, and Open Data, the sources traditionally purchased or licensed by the library are decreasing relative to scholarly information that is openly available. Enabled by the internet, a critical foundation for the Open Access Movement was established in 1991, with the formation of arXiv.org by Paul Ginsparg at the Los Alamos National Laboratory, making physics preprints freely available worldwide. ${ }^{1}$ With the arrival of the World Wide Web in the mid-1990s, both scholars and students were able to access library resources from almost anywhere-and increasingly other information sources, as well. The volume of scientific publishing outside traditional journals has grown, including increased open-access publications and online prepublication platforms. Adding to this, sharing of research data has become an essential component of research. In response to the current COVID-19 pandemic, these trends have only accelerated. ${ }^{2}$

\footnotetext{
${ }^{*} H$. Thomas Hickerson is Principal Investigator and former Vice Provost for Libraries and Cultural Resources and University Librarian at University of Calgary; email: tom.hickerson@ucalgary.ca. John Brosz is Data Visualization Coordinator at University of Calgary; email: jdlbrosz@ucalgary.ca. Leonora Crema is Scholarly Communications Librarian at University of British Columbia; email: leonora.crema@ubc.ca. (22022 H. Thomas Hickerson, John Brosz, and Leonora Crema, Attribution-NonCommercial (https://creativecommons.org/licenses/by-nc/4.0/) CC BY-NC.
} 
Changes in research have been transformational, and, although the impact has varied across disciplines, no area has gone unaltered. The transition to interdisciplinary and multidisciplinary research has created both new interdisciplinary clusters and research partnerships spanning such clusters. Changes have been further stimulated by funding agencies' promotion of "grand challenges" research in which the scope and complexity of inquiry necessitates diverse coalitions. Related in character and effect is the increasing emphasis on community-based research explicitly embedded in a sense of societal mission.

Equally impactful has been the extensive methodological change in research sources and products and in the analytical tools being employed. Research information recorded as electronic data has been common for decades, and software for statistical analysis is broadly applied. Paralleling this development in recent decades is spatial analysis. Geographic Information Systems (GIS) allow users to create interactive, user-created queries using visualization and visual analytics to address areas as diverse as astronomical, climatological, cultural, and historical investigations. Combined with text mining, computational analysis, $\mathrm{AI}$, and the integration of data generated by diverse disciplines, a new and different research ecosystem of shared, cited, and published resources has evolved.

In this rapidly changing landscape, libraries are facing a paradigm shift in the ways they contribute to achieving the research objectives of their universities. They are recognizing that traditional services and organizational models require fundamental reexamination if they are to fulfill these new roles.

A multiyear research project, funded by The Andrew W. Mellon Foundation and conducted at the University of Calgary, has sought to programmatically define a new model for the role of libraries within the research ecosystem. Notably, this project employed an evidence-based approach incorporating direct input from scholars and research leadership, with findings demonstrated through a series of real-time collaborative research projects and external review by an expert panel.

As a concluding step, the project hosted an international symposium to present its findings and those of other projects seeking to reimagine research services in academic libraries. ${ }^{3}$

Collectively, the project and its further deliberations integrating library and research administration perspectives offer important insights into what organizational transformations and new relationships will be needed to ensure academic libraries' future vitality in campus research.

\section{Literature Review}

In the past decade there has been considerable discourse about libraries' new roles in research and opportunities to engage throughout the research lifecycle. Changes in research methodologies have been the main motivating factor, including the rise of digital scholarship, ${ }^{4}$ an increase in multidisciplinary and interdisciplinary inquiry, and an emphasis on societal impact. Interest in research services office (RSO) partnerships has also grown. Studies of the implications for library practice are outlined under the themes below.

\section{Transformation of Librarian Roles}

In a 2008 CLIR study, librarians and other stakeholders convened to "rethink the research library in a dynamic, swiftly changing landscape dominated by digital technology." ${ }^{5}$ Case studies in Europe trace a similar shift. ${ }^{6}$ Bourg, Coleman, and Erway developed an academic 
library manifesto focusing on new areas of research support and issuing a call to action. ${ }^{7}$ Librarians at Cornell combined with Ithaka S+R to study A Day in the Life of the (Serious) Researcher, envisioning new service models. ${ }^{8}$

Perhaps the most examined issue has been the evolving nature of librarians' roles. In an RLUK study, Auckland explores the reskilling required for a changing research environment. ${ }^{9}$ In their landmark study, New Roles for New Times, Jaguszewski and Williams identified the increasingly hybrid and functional nature of liaison work. ${ }^{10}$ Discipline-based roles yielding to functional specialities are also noted in a study by Eldridge et al. ${ }^{11}$ and were realized by University of Manchester Library in a reorganization based on functional specialization (Hoodless and Pinfield; Bains). ${ }^{12}$ In 2014, examining new competencies for research engagement, Kenney advocates attention to scholars' needs and success indicators, and universities' focus on academic productivity. ${ }^{13}$ Around this time, a growing literature of digital scholarship librarianship emerges, along with further evolution of librarians' roles, as recently studied in the Canadian context by Ducas, Michaud-Oystryk, and Speare. ${ }^{14}$

\section{New Services, Spaces, Technologies}

Academic libraries have implemented new services and organizational models supporting research. Restructuring efforts at University of Arizona ${ }^{15}$ and University of California, Riverside were among those seeking to intensify involvement in research projects, data management, dissemination, and measuring impact. ${ }^{16} \mathrm{As}$ a touchpoint for services, research commons spaces began to emerge along with digital humanities and digital scholarship centers, focused on research support and development. ${ }^{17}$ Lippincott, Hemmasi, and Lewis documented developments in digital scholarship centers including their service and spatial attributes. ${ }^{18}$

Technological change has driven innovation; as early as 1999, Deckelbaum identifies GIS as a potent analytic tool for research problems across a broad array of disciplines. ${ }^{19}$ A 2007 Association of Research Libraries study describes developments in e-science and team science with implications for practice. ${ }^{20}$ Horstmann and Brase articulate libraries' roles in data-intensive research combining theory, experiment, and simulation. ${ }^{21}$ Sustaining this infrastructure is a challenge, prompting new campus partnerships and resource strategies linking collections and computational capacity expenditures (Orcutt, Davis, Raschke). ${ }^{22}$ Library embeddedness in research projects is taking new forms in areas such as research reproducibility ${ }^{23}$ and systematic reviews ${ }^{24}$ Fernández-Marcial and González-Solar offer recent case studies on models for library-research engagement. ${ }^{25}$

\section{Partnerships with Research Administration}

Relationships between libraries and research administration are less well examined. MacColl and Jubb note differences between the UK, where the RAE/REF dominate the researcher, librarian, and research administrator consciousness, versus North America where there is clearer division between librarian and research administrator roles. ${ }^{26}$ Bryant et al. also note jurisdictional differences, such as varying involvements in CRIS/RIM systems. ${ }^{27}$ However, bibliometrics are potential meeting points for libraries and research administration, more commonly in Europe, Australia, and the UK, and increasingly in North America. ${ }^{28} \mathrm{Krzak}$ and Tate describe Edinburgh University Library's collaboration with research administrators tracking open access compliance..$^{29}$ Knowledge mobilization is another intersection, as universities seek more public profile for their research. ${ }^{30}$ Universities worldwide are contributing to UNESCO 
Sustainable Development Goals, with Times Higher Education incorporating this new metric in its ranking systems. ${ }^{31}$

Studying campus reporting lines, Corrall notes growing tendencies to group libraries with student-facing and education-related services, "arguably not a positive move for libraries trying to reposition themselves as credible partners and collaborators in research activities." ${ }^{\prime 32}$ In a comparative review of the literatures of library and information science and research administration, Bradley finds limited awareness of the activities of the other, concluding they are working as "bounded" professionals, with only occasional forays into "cross-boundary" activities. ${ }^{33}$ However, Rieger and Schonfeld's recent study of senior research officers suggests there may be growing efforts to bridge these gaps. ${ }^{34}$

The research project conducted at the University of Calgary is based in this spectrum of multifaceted change, both illustrating the impact of such change on the role of libraries in research and demonstrating the outcomes of creating a new model.

\section{The Academic Research and University Libraries Project}

In 2015, recognizing the critical importance of evolving changes in academic research, the University of Calgary Library (Libraries and Cultural Resources) initiated a study to discern the infrastructure, expertise, and services most essential in supporting current research. Acknowledging the inadequacy of the disciplinary silos commonly used to organize staffing and services, investigations also focused on new integrative partnerships within the library and between the library and research administration. Calgary was well positioned to undertake such research by the completion in 2011 of a new technologically advanced central library structurally designed to incorporate ongoing change, including new spaces, technologies, and staff supports for learning and research.

With the support of the Vice President for Research and funding from The Andrew W. Mellon Foundation, the project began in November 2015 with three days of workshops designed to elicit perspectives and research support needs from groups of faculty researchers. Fifty researchers from 15 disciplines took part, focusing on the humanities and social sciences but also with representation from STEM fields:

- Anthropology

- Archaeology

- Architecture

- Chemical and Petroleum Engineering

- Civil Engineering

- Computer Science

- Environmental Design

- Geography

- Geology

- History

- Military, Security, and Strategic Studies

- Political Science

- Public Health

- Real Estate Studies

- Urban Planning Workshops were led by outside facilitators from elsewhere in Canada, the United States, 
and Australia. Three faculty researchers from other Canadian universities participated to broaden the scope of the discussions. A small number of library and Office of Research Services staff attended, but serving only as observers to remain at arm's length from the deliberations.

There was remarkable consensus among the participating scholars. The principal needs they identified included:

- Data Curation and Sharing

- Analytics and Visualization

- Metadata Services

- Digitization

- Rights Management and Dissemination

- Collaborative Spaces

Based on these initial findings, the next goal was to instantiate this constellation of services as a research platform capable of efficiently supporting a diversity of scholars and students.

Realizing this new paradigm was the focus of a new research grant, "Academic Research and University Libraries: Creating a New Collaborative Model," funded by The Andrew W. Mellon Foundation in 2017 and completed in February 2020..$^{35}$ The main objective of this project was to identify a new platform of library research services. But rather than further focus group studies or theorizing about the nature of scholars' needs, the project employed grants to fund internal faculty research projects that would allow scholars to work directly and iteratively with the library and thereby discover how services would be used.

Starting in the spring of 2017, two rounds of competitive, internal grants (subgrants) were issued to support University of Calgary research conducted in partnership with the library. Projects were required to employ multidisciplinary teams, actively engage with the library's emerging research platform, and conduct research within one of three overarching themes that were strategically important to the university:

- Smart Cities: investigations of sustainable, resilient, secure, and culturally dynamic cities;

- Arctic Studies: research of the North American and the circumpolar Arctic through the environmental and social sciences, the arts, and the humanities; and

- Cultural Discourse: multidisciplinary inquiry into the various aspects of artistic expression, communication modes, and societal traditions and norms.

The duration of the subgrants was limited (six to eight months) to encourage an intense time of learning and exploration for the scholars, as well as to provide the library an opportunity to quickly learn and apply the findings from the experience.

After initial adjudications based on a letter of intent, library staff met with research teams to ensure they were aware of the variety of potential areas of collaboration with the library and to assist in development of the full proposal. In many cases, these proposal meetings led to increased engagement with existing areas such as: metadata services (for instance, in training graduate students in metadata production and quality assurance); or making use of library resources in different ways (like having trained student assistants digitize material with the library's equipment rather than paying for outside technicians to complete this work); or drawing on new areas of library expertise in areas such as data visualization or geospatial analysis.

These meetings also identified a new requirement for the research service platform, which was development and preservation of moderately complex websites. This supported the public dissemination role needed by many projects. Rather than having research teams make use of student-created sites (often with quality concerns or challenges in maintainability) or 
commercial developers (expensive and time-consuming), the library offered the opportunity to make use of the library's web development team. Virtual reality (VR) was identified as another area where the library could provide useful enhancements to researcher capabilities.

Adjudication of subgrant proposals was overseen by a panel comprising senior library staff, senior researchers, and research administrators from across campus. Projects were selected on the quality of their:

- Research concept ( $40 \%$ of weighting)

- Alignment with and support for the library research platform $(30 \%)$

- Methodology, feasibility, and budgeting (30\%)

Successful projects were eligible for funding of up to $\$ 40,000$ (CAD). In the first round (2017-2018), five projects were approved; in the second (2018-2019), seven projects were funded. A total of $\$ 400,000$ was dedicated to funding subgrant research. Each project round was followed by an external review by library and research experts from the United States and Canada, as detailed below.

The coordination of this process and of the project support was managed by a library Project Coordinator. The Coordinator organized the proposal meetings, inviting the research team and all library staff that could potentially contribute to the project. With the announcement of successful applications, the Coordinator arranged kickoff meetings introducing the teams and library personnel and establishing project timelines and data management plans. Once the research was underway, the Coordinator served as a central contact for scholars and library staff to keep participants up-to-date, secure resources, and assist in resolving problems.

Additionally, the coordinator organized a half-day, midproject meeting between all the research groups, library contributors, and senior research administrators. This meeting featured presentations on current progress by all the research teams. In feedback, the researchers expressed appreciation for how this event informed teams about additional library resources and expertise that they could employ in their projects. These discussions also alerted research administrators to new research underway on campus and the roles being fulfilled by the library.

\section{Research Projects}

Over two years, 12 projects from 31 applications were funded and completed. The projects were diverse in scope and included scholars from many disciplines. Findings were significant, producing a broad array of outcomes. The projects ${ }^{36}$ included:

Open Data for a Smarter City: Creating a Data Infrastructure Pilot Initiative, led by Ryan Burns (Geography), created a data repository for local city data from researchers, community associations, nonprofits, and others. While the City of Calgary operates an open data portal, this new repository targets data outside the city's purview. http://yycdatacollective.ucalgary.ca/

Paper Traces in Digital Environments: Enhancing Analysis and Representation of Content and Materiality in Digitized Print Collections, led by Stefania Forlini (English), explored enhancing the digitization process and metadata records of the Bob Gibson Collection, 850+ hand-crafted anthologies of early speculative fiction. Existing mass digitization techniques focus on the text at the expense of material properties that can be essential to scholars' research (in speculative fiction it is important to differentiate low-cost "pulp" publications from high-cost "glossies"). This project explored mining the material archive ${ }^{37}$ by enhancing the digitization process, expanding the collected metadata, and incorporating macro photography of paper and ink to accentuate these collections' unique historic, aesthetic, and material qualities. http://stuffofsciencefiction.ca/ 
Digital Preserving Alberta's Diverse Cultural Heritage, led by Peter Dawson (Archaeology), created an online repository for three-dimensional scans of cultural heritage sites. The resulting website, developed by library staff with its content created and controlled by the research team, links to deposited datasets in the library's data repository. The associated data includes building information models that provide means to monitor at-risk heritage sites, as well as detailed imagery and 3D models within virtual reality applications for education and outreach. https://preserve.ucalgary.ca/

ArcticSensorWeb: A Research Platform for Real-Time Dissemination of Arctic Data, led by Brent Else (Geography), created a web portal to make scientists' weather and environmental sensor data available in real time to local communities in the Arctic. This included consultation to ensure that the data and visualizations were useful as well as accessible with low-bandwidth internet access. https://sensorweb.arcticconnect.ca/

Mapping Urban Healthscapes: Bringing Together Big Data and Empathic Cultural Maps in a Knowledge Transfer and Exchange Project, led by Suzanne Goopy (Nursing), developed empathic cultural maps to take accounts of qualitative immigrant experiences of city infrastructure and the health system and links these accounts to city and census data with the goal of more effectively communicating concerns to municipal and provincial policy-makers, community members, and educators. http://bit.ly/storymapecm

Mapping and Visualizing Victorian Literary Sociability, led by Karen Bourrier (English), examines how social networks influenced the careers of Victorian writers, artists, editors, and publishers, with a particular focus on women's careers. This team employed a variety of sources to compile geo-referenced data on the residences of Victorian writers, artists, editors, and publishers. This will inform the team's in-depth analysis of propinquity's effect on the literary careers of women in nineteenth-century London. https://victorians.ucalgary.ca/

Are Smart Cities Healthy? led by Jennifer Godley (Sociology), explores how a variety of Canadian cities compare with each other in terms of economic, health, social, and infrastructural factors. In sociology and public health, there is a tradition of studying how socioeconomic factors influence individual health; this project extends this by incorporating economic factors pertinent to building smart, sustainable cities.

Visualizing a Canadian Author Archive: Alice Munro, led by Murray McGillivray (English), explores the enhancement of finding-aid metadata and TEI encoding in conjunction with data visualization to enhance exploration of this significant collection. Beyond gaining a greater understanding of how these techniques can enhance digital humanities' methodologies, the research team specifically investigated Alice Munro's methods for drafting and refining her stories and the effects of publisher feedback on 14 of her short stories. https:// library.ucalgary.ca/munroarchiveproject

Soper's World: A Journey into the Canadian Arctic through Art, led by Maribeth Murray (Anthropology and Archaeology), explores naturalist and explorer Dewey Soper's multifaceted role in the Arctic and highlights Canadian Arctic exploration. Through digitization of his paintings and a virtual exhibit mapping Soper's explorations, this project combines geography, art, history, and biology to create an educational window on the Arctic for the public. The virtual exhibit provides a variety of content for teaching and outreach. https://www.arcgis. com/apps/Cascade/index.html?appid=936ecf2673ae4ffb9f33b0b1ac8752ed

Making Specialized Natural History Collections Accessible to Diverse Users: A Case Study Involving the Bees of Alberta, led by Mindi Summers (Biology), seeks to address the 
need for biodiversity by developing an open-access platform providing data on Albertan bees, including project-created, high-resolution images, to scientists, city planners, and interested members of the public. The project also developed guides to support nonscientific users in exploring this collection and answering questions related to biodiversity, local bee populations, and resources on bio-inspired urban design. https://biodiversity.ucalgary.ca/

Preserving and Disseminating Maker Skills with Mixed-Reality Videos, led by Anthony Tang (Computer Science), seeks to assist learners in becoming effective users of makerspaces by using mixed-reality videos that ease self-learning. To move beyond 1:1 teaching in makerspaces, this project explores new communication modes-specifically, how mixed-reality technologies can be used to preserve knowledge of and to acquire skills with makerspace tools. These explorations will result in new forms of videos that prospective learners can use and study to learn how to use maker skills. One of the produced videos from the project is available at https://prism.ucalgary.ca/handle/1880/110506.

SmartCampus: Interactive Visualizations for Data-driven Design, led by Wesley Willett (Computer Science), explores interactive data visualization of phone-GPS data from university students with the goal of providing tools for campus designers and architects. Four design sessions with practicing architects explored prototype visualizations, gathering insights on how these data and visualizations may answer and guide questions on campus design. https:// smartcampus.ucalgary.ca/

\section{Project Findings and Evaluation Library Staff Experience}

Several findings related to the experiences of library staff, approximately $45 \mathrm{in}$ all, who contributed to the projects. Particularly notable was staff appreciation of the opportunity to engage directly with researchers, employing their expertise and developing new skills. For example, the library's newly hired metadata librarian was surprised to move beyond a collection support role and have an opportunity to engage with a variety of research projects immediately upon starting the position. The manager of the metadata unit noted that her staff, a group with deep expertise working with bibliographic material but without much experience with datasets and other "born-digital material," were highly engaged and concluded that this initiative led them to be more aligned with the university's mission and goals. Despite sometimes stretching their expertise into new areas, library staff found that researchers were both comfortable and confident in their capacities.

Another important aspect of the staff experience was building relationships with researchers. The ability to engage with researchers in project meetings before the research proposal was finalized was unique and contributed to the quality of the projects. It allowed library personnel to provide more fulsome support, often incorporating technology or services that the research team did not initially consider. Researchers noted how their research topics were sometimes reframed based on conversations with library staff. There was also cross-learning within the library (such as personnel in data curation and visualization developing workshops and design sessions that integrated new knowledge into research projects).

For library units supporting these projects, a new style of collaboration developed. o Whereas a digitization project formerly would be driven entirely by the digitization group, in this process they now shared responsibility for these projects with other units (such as metadata, web development, and copyright). This increase in cooperative efforts also high- 
lighted some shortcomings in the library's project support infrastructure, particularly the lack of secure, short-term file storage and transfer capabilities and project tracking. In the second round of projects, the library employed new systems (Trello for tracking projects and a new file server for sharing files) to improve these processes.

\section{Researcher Experience}

In their post-project reporting, the subgrant investigators provided crucial feedback. One important aspect of collaborating on research with the library is that the library must avoid a "one-size-fits-all" approach, instead prioritizing openness to exploration and the tailoring of services to the needs of the research. Researchers also expressed needs for ongoing support from the library for continued distribution of research outcomes beyond the lifespan of the short-term research team. Participating scholars especially valued the variety of spaces in libraries, which they found useful for facilitating collaboration with both university and community partners and for conducting project events.

The Project Coordinator was seen as particularly helpful in ensuring the project partnerships were fulsome. The Coordinator was able to find further expertise and resources and assisted in keeping collaborations on track. But despite the Coordinator's role in helping to secure services, there were challenges determining library collaborators' scope of expertise and time capacity to contribute to research projects.

The research teams also remarked that the short timelines of these projects (6-8 months) led to challenges in initiating their projects, particularly finding and hiring research assistants.

\section{Implementing the Platform}

Figure 1 illustrates the components of the library research platform used by the research projects. Data curation, metadata services, and collaborative spaces were widely used throughout the majority of the projects; digitization, visualization, and web development were used by almost half of the projects.

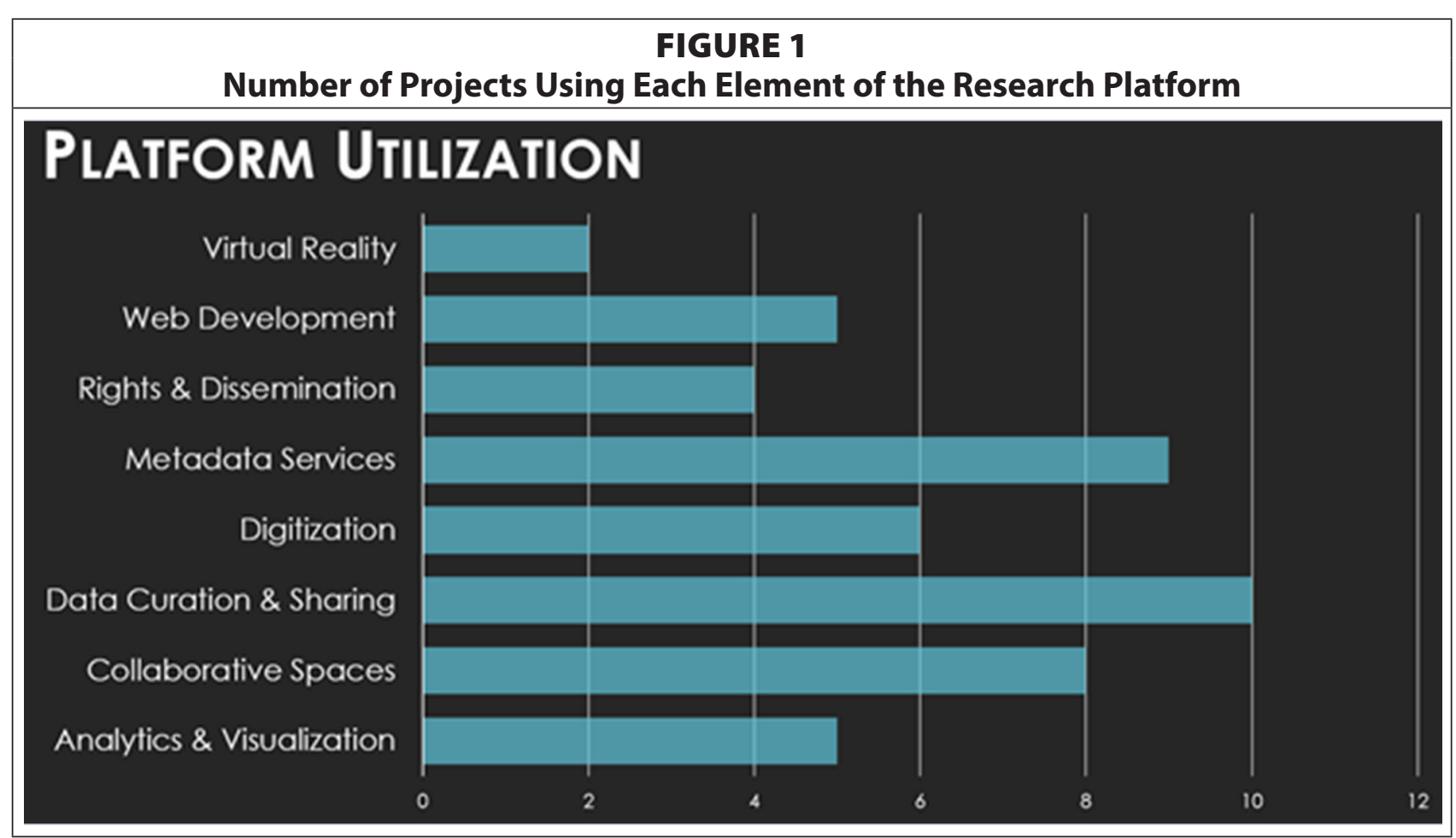


Beyond demonstrating how the research platform complemented current research practices, this initiative also demonstrated how it could be useful across a variety of campus disciplines. The research teams involved scholars from nine faculties/institutes (Architecture, Planning and Landscape, Arctic Institute of North America, Arts, Business, Education, Engineering, Medicine, Nursing, and Science) drawing on 28 different departments. As the platform components are not tied to specific disciplines, they can provide important economies-of-scale benefiting a variety of scholars.

Collaborative space is an important element within the research platform. Projects made use of space in different fashions. Some made use of the library's newly launched Lab NEXT ${ }^{38}$ as a working space where students and scholars from different disciplines could gather when they did not have sufficient departmental space of their own. ${ }^{39}$ Others made use of library spaces such as the Visualization Studio, the Makerspace, and other areas for functions such as launch events, design sessions, meetings, and workshops. Even in this time of COVID-19, researcher interest in digital research skills and analytical tools remains high, and training sessions can occur in an online-only environment.

An important consideration for establishing the research platform is the degree to which it builds upon services, infrastructure, and expertise that already exists within academic libraries. The approach taken was to craft these functions into a singular user-experience, essentially a one-stop approach, so that researchers could discover and more effectively use these resources in combination and did not need to navigate internal complexities of the library.

Feedback from both the research teams and library staff strongly supported this approach. Particularly appreciated was the Coordinator's role in acting as a central point of contact, in both directions, to resolve issues and ensure projects proceeded as planned. Research and library staff both noted that frequent meetings were essential to the success of the collaborative endeavor. The value of data management plans to encourage early discovery of infrastructure and service needs was also recognized.

\section{External Review}

Essential to validating the findings at Calgary were the external reviews conducted at the conclusion of each round of funded research projects.

The External Review team included Larry Alford (University of Toronto), Charles Eckman (University of Miami), Lorcan Dempsey (OCLC), Harriette Hemmasi (Brown University), Megan Meredith-Lobay (University of British Columbia), Shan Sutton (University of Arizona), and Joan Lippincott (Coalition for Networked Information, CNI). In both May 2018 and September 2019, the Review team met with the project researchers, library teams that had participated in the projects, and research administrators. Findings from the Review were very positive, and the reviewers encouraged broad dissemination of project findings.

Principal observations from the review team included the following:

- the critical importance of conveying the depth and breadth of library services and expertise to researchers;

- that new models of collaboration are essential library-to-researcher but also among library departments;

- that interaction with research administrators is needed to articulate and incorporate this redefinition of the library's role throughout the research lifecycle;

- the openness of librarians to redefining their understanding of researcher needs; 
- the importance of the Project Coordinator, supported by a core team of advisors from the library and the Research Services Office, facilitating the work of all project participants; and

- issues surrounding the scalability and sustainability of this new model.

In concluding their report, the External Review Committee wrote: “The ultimate measure of success in repositioning the library in the research enterprise occurs when faculty come to the library not because they are given a financial incentive but rather, when they perceive the services provided and partnership potential as things that they truly need. The University of Calgary Library has done tremendous work in re-establishing the library's perception and reality in our changing environment." ${ }^{40}$

\section{Symposium Combining Library and Research Leadership Perspectives}

Concluding the Academic Research and University Libraries: Creating a New Model for Collaboration Project, a symposium was conducted to provide an opportunity for active engagement by a diverse audience of library and research professionals. The Symposium was held December 11, 2019 in Washington, DC, and was organized by a team including the Calgary principal investigator and leaders of other important projects exploring new roles in research. Three Vice-Presidents/Associate Vice-Presidents for Research presented their views and offered reflections throughout the day. Attendees included 120 attendees from 86 institutions in the United States and Canada, as well as attendees from France, Germany, and Nigeria.

In his opening comments, Thomas Hickerson enunciated the programmatic mission being addressed: "In so many ways - whether in organizations still modelled on a print paradigm, in the utilization of staff, and in the image that libraries have on many of our campuses - I believe we are behind the pace of change. And yet, research continues to evolve. If we do not create a new prism through which to envision and realize a redefined role, our role in this vital area will diminish. This is the urgency, and this is why we are here today." 41

\section{New Collaborations with Campus Research}

Wolfram Horstmann, Director of the Göttingen State and University Library at Georg-AugustUniversity of Göttingen, delivered the opening keynote. He noted that, with research becoming more collaborative, distributed, and data-intensive, institutions must adapt internally and seek external collaboration with peers. He described the eResearch Alliance, ${ }^{42}$ a new service at Göttingen in which the library, computing, and the research office partner to provide onestop research technology support. The library is pooling its resources with others, thereby strengthening local expertise and infrastructure.

The keynote was followed by a session moderated by Mary Lee Kennedy, Executive Director of the Association of Research Libraries, in which speakers highlighted recent initiatives to engage libraries with research. Charles Eckman, Dean and University Librarian, described the University of Miami's library interactions within multidisciplinary research teams organized to address challenges presented by UNESCO sustainable development goals as part of their U-LINK ${ }^{43}$ initiative. Xuemao Wang, Vice Provost of Digital Scholarship and Dean and University Librarian, spoke about new alignments between the library and research through their Digital Scholarship Center and Research Data Center at the University of Cincinnati. ${ }^{44}$ Thomas Hickerson concluded the panel, describing the underlying research conducted at Calgary in which scholars defined principal needs enabling today's interdisciplinary research. 
These comments were followed by responses by senior research administrators from the respective institutions: Susan Morgan, Associate Provost for Research Development at the University of Miami; Pat Limbach, Vice President for Research at the University of Cincinnati; and Penny Pexman, Associate Vice-President (Research) at the University of Calgary. All saw libraries' value as partners, collaborating with researchers and disseminating their work in new ways. Library staff can also help faculty in enhancing their technology skills, often a challenge due to lack of available time. Administrators agreed that experimentation is essential and that change must encompass all aspects of library space, staffing, and organization. In response to audience questions about the risks of enacting such change, Eckman replied, "The risk is in not experimenting and making these changes - that is the high-risk strategy."

\section{Strategies for Transformation}

The next panel, moderated by John Brosz, Project Coordinator at the University of Calgary, focused on key strategies for aligning libraries with research. Joy Kirchner, Dean of Libraries at York University, described a multiyear reorganization of the library on functional rather than disciplinary lines. Greg Raschke, Senior Vice Provost and Director of Libraries at North Carolina State University, spoke of the need to reexamine the purpose and allocation of collections funding. Today, research resources are not just collections; they are also the computational infrastructure that researchers need to analyze and work with them. Leonora Crema, Scholarly Communications Librarian at the University of British Columbia, described recent collaborations with research services administering an internal grant, promoting the community impacts of research, and in researcher identity systems. She urged libraries to shift attention from research discovery (what can our researchers access) to researcher discovery (who accesses their work and how).

\section{Plenary Discussion and Areas for Focus}

Presentations were followed by plenary discussions, moderated by Joan Lippincott, Associate Executive Director, CNI. Attendees identified other strategies for change: what would they advocate at their own institutions? What might the challenges be? In lively afternoon breakout sessions, attendees discussed these issues, and common areas of interest emerged:

- Partnering with research administration. If libraries are to draw a clearer link between their activities and research outcomes, closer ties are essential. Starting points include collaborating on research impact, faculty development, research policy, and shared digital infrastructure.

- Collaboration to create a single customer-facing service for research computing. This was viewed as a compelling model, one that elevates the library's expertise in the institution and improves what, for researchers, can be a siloed experience.

- Reorganization including more functional expertise. Many libraries are already making such shifts: but how can we grow functional capacities while maintaining effective disciplinary connections?

- Building new staff competencies. Dedicated training, cross-departmental internships, meet-ups, and mentorships were among the ideas mentioned. Library and information science curriculum also plays a part.

- Space. Digital scholarship centers have become a venue for engaging students and faculty in research. How will libraries sustain these and other innovations, including the 
programming and partnerships to make these spaces successful?

- Collection as platform. Reimagining investment brings challenges but also opportunities to buy and build the corpus, provide new analytics and tools for community engagement, and help researchers create machine-actionable content in reproducible open formats.

- Research impact analysis. Universities care about this, and so should libraries. Some are developing new metrics supports for their campuses. The ability to demonstrate impacts of publicly funded research will be increasingly important.

- Transinstitutional library collaboration. Many libraries are already undertaking collaborative infrastructure investments and have experience in areas such as shared governance.

- Funding models, workloads, and measurements for prioritization. As we build these new partnerships and platforms, how do we sustain the other missions of the library? What takes priority? What are the new terms for success?

- Communicating new roles. At many points in the day, attendees wondered if researchers and university leaders recognize the new capacities that exist in libraries today. Libraries need a succinct new way of telling their story. OCLC's Lorcan Dempsey summed it up by saying that libraries "used to have a short elevator speech. Today that speech requires a very tall building."

\section{Research Administrators Respond}

Susan Morgan and Penny Pexman reflected on the day's deliberations. They agreed that for most universities, research funding and impact are core. Libraries can contribute by identifying where campus scholarship is particularly robust, using traditional metrics but also altmetrics and new qualitative approaches. Research intelligence is another priority. In areas where the university has research strength, how can this be marshalled to new areas of funding support? When a call for partnership in an area such as "healthy cities" comes out, who are our strongest collaborators? The tools and networks libraries already have access to can prove valuable assets here.

There is clearly a role for libraries in faculty development and training in digital tools. The spaces libraries are creating with their central locations, cross-disciplinary meeting places, and specialized technology can support and showcase faculty work. Multidisciplinary research teams can sometimes experience translational challenges. Librarians are comfortable in this arena, cutting across differences and leveraging commonalities of interest.

\section{Closing Observations}

In summary remarks, Clifford Lynch, Executive Director of CNI, affirmed that today's research landscape is complex, and the challenges are many. As libraries are adopting these new roles, it will be "and" not "instead of" our role sustaining the scholarly record. He urged thinking five years out, to what research will look like, and to the funding models necessary for new infrastructure as a complement to the resources we already invest in.

\section{Professional Implications}

Through the various components of this study - the researcher workshops, the funded research projects, and the multistakeholder symposium that followed-overlapping themes emerged, as did a sense of urgency for change. It is clear that libraries are recognizing the critical need to redefine, redirect, and reposition their presence in the research lifecycle on their campuses and beyond. 


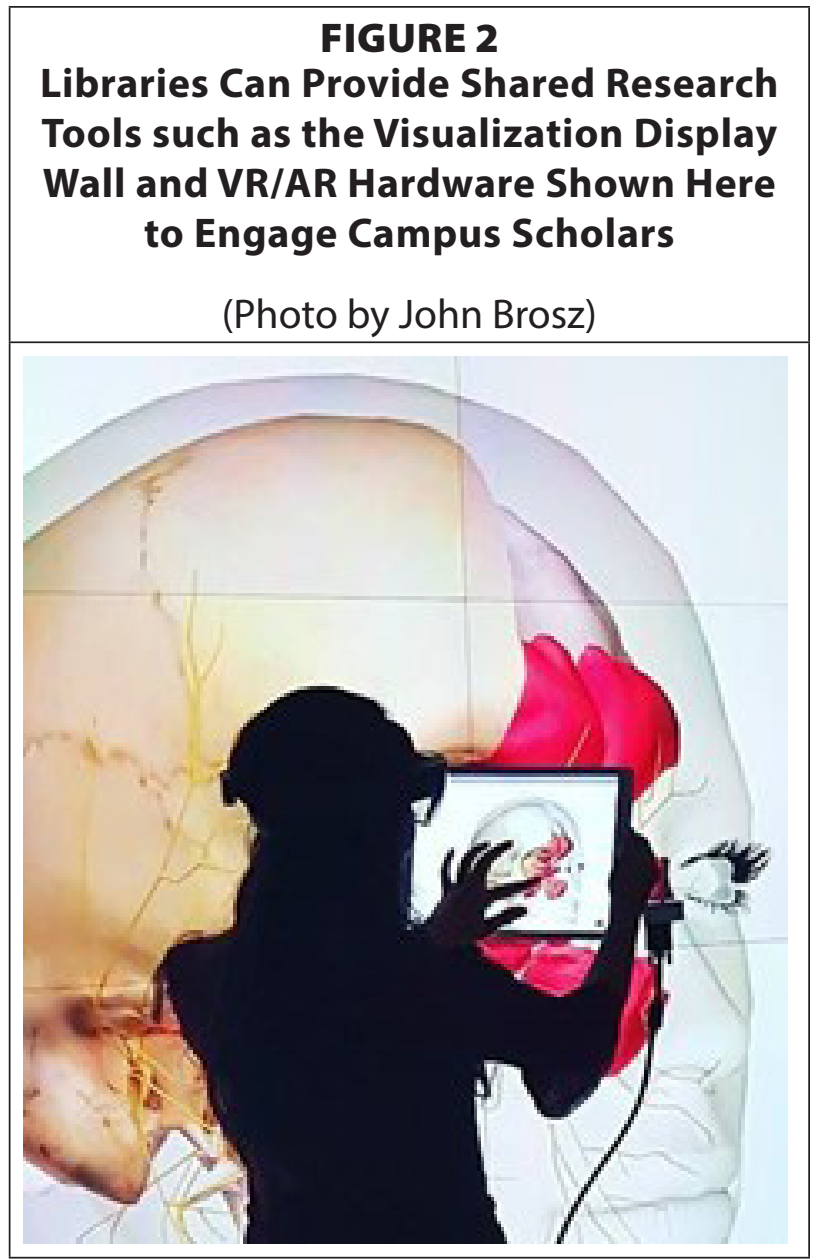

FIGURE 3

A Scholar Engaged in a User Experience Study in the Library Creates a Dynamic Research Experience

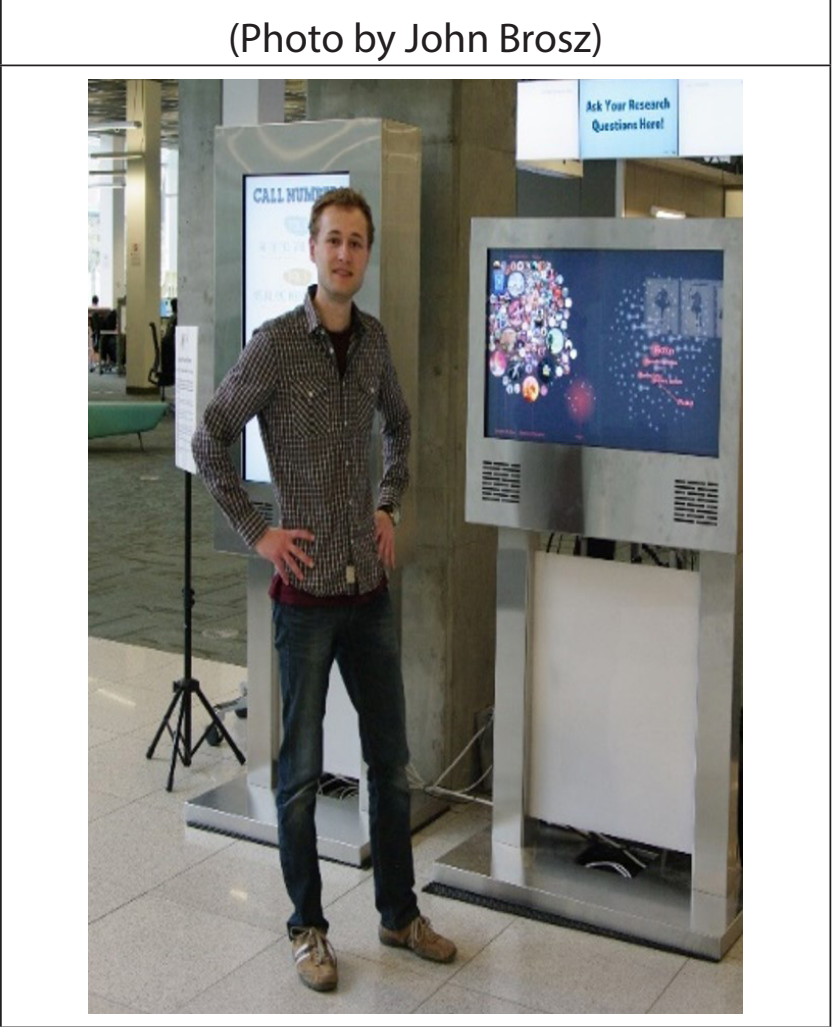

The changes that will be required are fundamental, and will include making strategic shifts in these areas:

\section{Digital Media and Analytical Tools}

The information sources scholars use today are increasingly valued in direct association with the analytical tools that enable research. In a new paradigm, libraries' choices about content should increasingly be linked to these analytical capacities (see figure 2). Directly linking these investments will create a New Synthesis driving collection decisions and expenditures. ${ }^{45}$

\section{Disciplinary to Functional}

Organizational structure and services should be redesigned to strengthen library functional capacities, with less focus on traditional disciplinary roles. ${ }^{46}$ Cross-disciplinary platforms can serve multiple needs both on and beyond campus.

\section{Research Resources to Research Experiences}

Focus attention on the nature of research today, rather than on acquisition of those resources that libraries have invested in historically. Today's research sources are often drawn from beyond what libraries purchase or licence, especially in an age of Open Science. Research platforms will continue to change, so we must employ an evidence-based response to current research practice and needs (see figure 3). 
Partnerships Rather than Transactions Stop counting and start building relationships. Libraries must be involved in all stages of the research lifecycle, not just capturing the end products of research. Library staff should pursue deep partnerships in the research process, offering expertise, infrastructure, and interdisciplinary collaboration (see figure 4). This may not align well with traditional, transactional service models.

\section{Reducing the Cost of Research}

Libraries offer inherent efficiencies in applying shared resources-expertise, infrastructure, and services - to enhance the impact and value of research investments. One research project lead investigator, cultural anthropologist and Associate Professor of Nursing Suzanne Goopy,

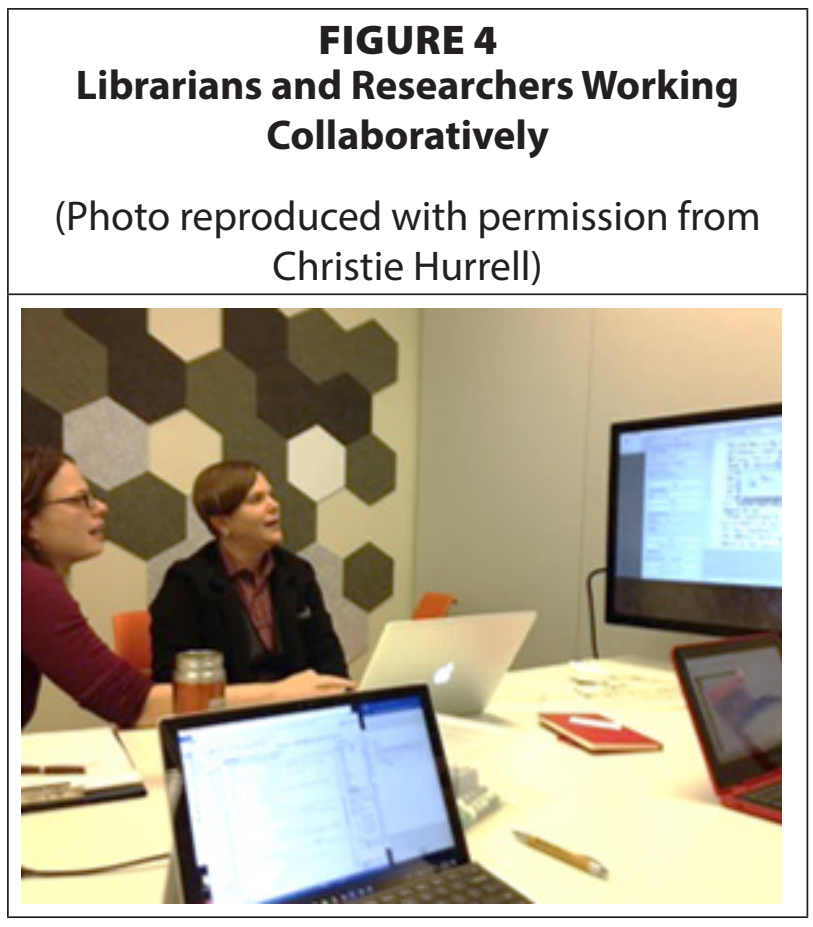
reported that using library services to support her research rather than other means cut the cost of her project from $\$ 100,000$ to $\$ 30,000$. These kinds of savings can make a significant difference in the scope of a project and have broad institutional implications.

\section{Collaborative Spaces}

Library spaces are becoming labs serving as hubs for discovery and creation. ${ }^{47}$ Increasingly, they will feature constellations of research services, linking throughout the library, across campus, and with communities in support of socially engaged scholarship. Planning should incorporate principles of openness and permeability, ${ }^{48}$ with research leadership as key partners.

\section{Conclusion}

In the five years of this project, evidence-based inquiry determined principal components of a research platform designed to address researchers' current needs. Through substantive research conducted by a diversity of scholars working in combination with library staff, services, and infrastructure, critical new alignments were created. Researchers developed a new understanding of library expertise and services. And critically important to the repositioning of the role of the library, research administrators and research services staff developed an expanded awareness of potential contributions to the research enterprise.

The experience and findings of the project have been systematically reviewed and broadly disseminated. Parallel investigations have been conducted elsewhere, and common findings have been incorporated into professional practice and policy. Library organizations worldwide are devoting increased attention to recreating a central role for libraries in the research lifecycle. ${ }^{49}$ On many campuses, new collaborative models in which libraries, research computing, and research services combine to provide a single point of intersection with the research process are being successfully implemented. 
In the coming years, libraries may remain valuable learning spaces, but their importance and financial support will decrease without a central role in the research enterprise. Fundamental change is essential in realizing the potential for libraries to attain enhanced relevance in academic research. But the redefinition and repositioning of the library also requires institutional change. An expanded partnership with research administration and research services is critical, and most important is shared understanding and active collaboration campuswide.

The required organizational changes will be transformative, but attainable. Much of the needed infrastructure and expertise is already present in libraries and awaits rechanneling into new roles. Libraries already embody elements critical to success in addressing such challenges:

- Trust-A record of responsible stewardship;

- Neutrality-Exercising a campuswide mission;

- Universality-Employing common methods and standards; and

- Economies-of-Scale-One solution/multiple uses.

Ongoing redesign of the library environment in ways responsive to evolving needs will be essential, seeking opportunities to reshape scholars' vision of the library and to have their experiences reshape the library.

Through this new paradigm, libraries will remain relevant in academic research and reestablish their vital bonds with scholars. As research project lead Professor Goopy concludes: "I used to come to the library for the books and journals. These days, I come for the people." 50

\section{Acknowledgments}

The authors wish to acknowledge the support of The Andrew W. Mellon Foundation, particularly Donald J. Waters, former Senior Program Officer; Edward McCauley, former Vice President for Research, University of Calgary, for his project sponsorship supported by Research Services, coordinated by Robin Smith; all the scholars who contributed to the workshops and the multidisciplinary teams in the funded research projects; and Libraries and Cultural Resources staff contributing to the project, particularly Kerri Calvert, Mary McConnell, Susan Powelson, and Kathryn Ruddock.

\section{Notes}

1. Paul Ginsparg, "ArXiv at 20," Nature 476 (2011): 145-47, https://doi.org/10.1038/476145a.

2. Damien Grapton, "COVID-19 Pandemic Shakes Up the World of Scientific Publishing," University Affairs (July 2020), https://www.universityaffairs.ca/news/news-article/covid-19-pandemic-shakes-up-the-world-of-scientific-publishing/.

3. John Brosz, "Proceedings of the Critical Roles for Libraries in Today's Research Enterprise Symposium," University of Calgary (January 2020), http://hdl.handle.net/1880/111585.

4. Christine Borgman, Scholarship in the Digital Age: Information, Infrastructure and the Internet, (Cambridge, MA: MIT Press, 2007).

5. Council on Library and Information Resources, "No Brief Candle: Reconceiving Research Libraries for the 21st Century," Council on Library and Information Resources (2008), https://www.clir.org/wp-content/uploads/ sites/6/2016/09/pub142.pdf.

6. See, for example, Lotta Haglund and Per Olsson, "The Impact on University Libraries of Changes in Information Behavior among Academic Researchers: A Multiple Case Study," Journal of Academic Librarianship 34, no. 1 (2008): 52-59, https://doi.org/10.1016/j.acalib.2007.11.010.

7. Chris Bourg, Ross Coleman, and Ricky Erway, "Support for the Research Process: An Academic Library Manifesto," OCLC Research (2009), https://www.oclc.org/content/dam/research/publications/library/2009/2009-07. pdf. 
8. Kornelia Tancheva et al., "A Day in the Life of a (Serious) Researcher: Envisioning the Future of the Research Library," Ithaka S+R (March 2016), https://doi.org/10.18665/sr.277259.

9. Mary Auckland, "Re-skilling for Research: An Investigation into the Role and Skills of Subject and Liaison Librarians Required to Effectively Support the Evolving Information Needs of Researchers," Research Libraries UK (2012), https://www.rluk.ac.uk/wp-content/uploads/2014/02/RLUK-Re-skilling.pdf.

10. Janice M. Jaguszewski and Karen Williams, “New Roles for New Times: Transforming Liaison Roles in Research Libraries," Association of Research Libraries (2013), https://www.arl.org/wp-content/uploads/2015/12/ nrnt-liaison-roles-revised.pdf.

11. Jeanette Eldridge et al., “Strategic Engagement: New Models of Relationship Management for Academic Librarians," New Review of Academic Librarianship 22, no. 2/3 (2016): 160-75, https://doi.org/10.1080/13614533.2016 .1193033 .

12. Catherine Hoodless and Stephen Pinfield, "Subject vs. Functional: Should Subject Librarians Be Replaced by Functional Specialists in Academic Libraries?" Journal of Librarianship and Information Science 50, no. 4 (2018): 345-60; Simon Bains, "Manchester's New Order: Transforming the Academic Library Support Model," Research Libraries UK (2014), https://www.rluk.ac.uk/manchestersneworder/.

13. Anne R. Kenney, "Leveraging the Liaison Model: From Defining 21st Century Research Libraries to Implementing 21st Century Research Universities," Ithaka S+R (March 2014), https://sr.ithaka.org/wp-content/ uploads/2014/03/SR_BriefingPaper_Kenney_20140322.pdf.

14. Ada Ducas, Nicole Michaud-Oystryk, and Marie Speare, "Reinventing Ourselves: New and Emerging Roles of Academic Librarians in Canadian Research-Intensive Universities," College \& Research Libraries 81, no. 1 (2020), https://doi.org/10.5860/crl.81.1.43.

15. Ricardo Andrade and Raik Zaghloul, "Restructuring Liaison Librarian Teams at the University of Arizona Libraries, 2007-2009," New Library World 111, no. 7/8 (2010): 273-86, https://doi.org/10.1108/03074801011059911.

16. Ann Frankel et al., "Moving from Subject Specialists to a Functional Model," Research Libraries Issues 294 (2018): 53, https://doi.org/10.29242/rli.294.

17. Rebecca Dowson, "Research Commons: Site of Innovation, Experimentation, and Collaboration in Academic Libraries," Scholarly and Research Communication 7, no. 2 (2016): 6, https://doi.org/10.22230/src.2016v7n2/3a259.

18. Joan Lippincott, Harriette Hemmasi, and Viv Lewis, "Trends in Digital Scholarship Centers," EDUCAUSE Review (June 16, 2014), https://er.educause.edu/articles/2014/6/trends-in-digital-scholarship-centers.

19. David Deckelbaum, "GIS in Libraries: An Overview of Concepts and Concerns," Issues in Science and Technology Librarianship, no. 21 (1999), http://webdoc.sub.gwdg.de/edoc/aw/ucsb/istl/99-winter/article3.html.

20. ARL Joint Task Force on Library Support for E-Science, "Agenda for Developing E-Science in Research Libraries," Association of Research Libraries (2007), https://www.arl.org/wp-content/uploads/2007/12/esciencereport-final-2007.pdf.

21. Wolfram Horstmann and Jan Brase, "Libraries and Data: Paradigm Shifts and Challenges," Bibliothek Forschung und Praxis 40, no. 2 (2016): 273-77, https://doi.org/10.1515/bfp-2016-0034.

22. Darby Orcutt, Hilary Davis, and Greg Raschke, "Collections as Platform: Synthesizing Content, Computation, and Capacity," EDUCAUSE Review (August 10, 2020), https://er.educause.edu/articles/2020/8/collectionsas-platform-synthesizing-content-computation-and-capacity.

23. Franklin Sayre and Amy Riegelman, "Replicable Services for Reproducible Research: A Model for Academic Libraries," College \& Research Libraries 80, no. 2 (2019), https://doi.org/10.5860/crl.80.2.260.

24. See, for example, Genevieve C. Gore and Julie Jones, "Systemic Reviews and Librarians: A Primer for Managers," Canadian Journal of Library Information Practice and Research 10, no. 1 (2015), https://doi.org/10.21083/ partnership.v10i1.3343.

25. Viviana Fernández-Marcial and Llarina González-Solar, "Preface," in Cases on Research Support Services in Academic Libraries: Peking University Library, eds. Yong Tang, Chunhong Zhang, Viviana Fernández-Marcial, and Llarina González-Solar (Hershey, PA: IGI Global, 2021), https://oi.org/10.4018/978-1-7998-4546-1.ch011.

26. John MacColl and Michael Jubb, "Supporting Research: Environments, Administration and Libraries," OCLC Research (2011), https://www.oclc.org/content/dam/research/publications/library/2011/2011-10.pdf.

27. Rebecca Bryant et al., "Practices and Patterns in Research Information Management: Findings from a Global Survey," OCLC Research (2018), https://doi.org/10.25333/BGFG-D241.

28. An excellent example of library collaboration with research services in this area may be found in University of Waterloo Working Group on Bibliometrics, "Winter 2016 White Paper on Bibliometrics, Measuring Research Outputs through Bibliometrics," University of Waterloo (2016), https://doi.org/10.13140/RG.2.1.3302.5680.

29. Anna Krzak and Dominic Tate, "Large Scale Implementation of Open Access: A Case Study at the University of Edinburgh's College of Medicine \& Veterinary Medicine," Journal of EAHIL 12, no. 2 (2016): 8-12, https:// era.ed.ac.uk/bitstream/handle/1842/16058/EAHIL\%20Krzak\%20Tate.pdf. 
30. Lupin Battersby et al., "Institutional Systems \& Structures for Knowledge Mobilization: Bringing Worlds Together to Support Knowledge Mobilization" (catalyst roundtable presentation at the Canadian Knowledge Mobilization Forum, Vancouver, Canada, 2020), https://summit.sfu.ca/item/20833.

31. Ellie Bothwell, "THE Developing Ranking Based on Sustainable Development Goals," Times Higher Education (September 6, 2018), https://www.timeshighereducation.com/news/developing-ranking-based-sustainabledevelopment-goals.

32. Sheila Corrall, "Designing Libraries for Research Collaboration in the Network World: An Exploratory Study," LIBER Quarterly 24, no. 1 (2014): 17-48, https://doi.org/10.18352/lq.9525.

33. Cara Bradley, "Research Support Priorities of and Relationships among Librarians and Research," Evidence Based Library and Information Practice 13, no. 4 (2018): 15-30, https://doi.org/10.18438/eblip29478.

34. Oya Y. Rieger and Roger C. Schonfeld, "The Senior Research Officer: Experience, Role, Organizational Structure, Strategic Directions, and Challenges," Ithaka S+R (December 1, 2020), https://doi.org/10.18665/sr.314490.

35. The website for the project: https://library.ucalgary.ca/libraryresearchplatform.

36. Full project listings can be found at https://library.ucalgary.ca/libraryresearchplatform/2017subgrants and https://library.ucalgary.ca/libraryresearchplatform/2018subgrants.

37. Stefania Forlini, Uta Hinrichs, and John Brosz, "Mining the Material Archive: Balancing Sensate Experience and Sense-Making in Digitized Print Collections," Open Library of Humanities 4, no. 2 (November 23, 2018): 1-36, https://doi.org/10.16995/olh.282.

38. The website for LabNEXT: https://library.ucalgary.ca/labnext.

39. Thomas Hickerson and Leonora Crema, "Reinventing Libraries for Research in the Digital Age," Research Fortnight (March 2019), https://www.researchresearch.com/news/article/?articleId=1380306.

40. Larry Alford et al., "Transforming the Role of Academic Libraries in Multidisciplinary Research: Final Report of the External Review Team," University of Calgary (December 2019).

41. Brosz, "Proceedings of the Critical Roles for Libraries in Today's Research Enterprise Symposium," 2.

42. Jens Dierkes and Ulrike Wuttke, "The Göttingen EResearch Alliance: A Case Study of Developing and Establishing Institutional Support for Research Data Management," International Journal of Geo-Information 3, no. 8 (2016): 133, https://doi.org/10.3390/ijgi5080133.

43. Lisa Baker and Kelly Miller, "Sailing Together at the University of Miami: How New Campus Partnerships Are Leading to the Transformation of Librarian Roles in Learning and Research," in Proceedings of the IATUL Conferences (2019), https://docs.lib.purdue.edu/iatul/2019/strategic/2.

44. The website for the University of Cincinnati's Digital Scholarship Center: https://dsc.uc.edu/.

45. Thomas Hickerson, "A New Synthesis: Research Resources to Research Experiences," in Charleston Conference Proceedings (West Lafayette, IN: Purdue University Press, 2020), https://doi.org/10.5703/1288284317153; Orcutt, Davis, and Raschke, "Collections as Platform."

46. Examples of descriptions of libraries undergoing this transition include: Simon Bains, "Teaching 'Old' Librarians New Tricks," SCONUL Focus 58 (2013): 8-11; Ann Frenkel et al., "Moving from Subject Specialists to a Functional Model," Research Library Issues, no. 294 (2018): 39-71, https://doi.org/10.29242/rli.294.5; and Eldridge et al., "Strategic Engagement."

47. Tancheva et al., "A Day in the Life of a (Serious) Researcher."

48. Joan Lippincott, Kelly Miller, and Thomas Hickerson, "Purposeful Space Design for Libraries" (presented at the CNI Spring 2019 Project Briefing, St. Louis, MO, April 2019), https://vimeo.com/338031582.

49. Conclusions aligning with the findings of the research being conducted at the University of Calgary are being recognized widely. In 2017, the Association of Research Libraries, the principal such body in the United States and Canada, initiated the development of new membership principles reflecting the primary "Elements for Success as a 21st Century Research Library." In articulating new and evolving roles and responsibilities, the inclusion of criteria specifically addressing the role of libraries as "strategic and engaged partners in the research ecosystem" was among those mandated. The new Principles (https://www.arl.org/wp-content/uploads/2019/05/2018.04.24-PrinciplesOfMembership.pdf) were adopted unanimously at the Spring 2018 ARL Membership Meeting.

50. Thomas Hickerson, John Brosz, and Suzanne Goopy, "What Is the Future of Libraries in Academic Research?" (presented at the Coalition for Networked Information [CNI] Fall Meeting 2018, Washington, DC, December 2018), http://hdl.handle.net/1880/111624. 